\title{
Study on Design Method for Linkage Mechanism Size Parameters of Crawler Crane Superlift Mechanism Based on Genetic Algorithm
}

\author{
Jia Li ${ }^{1, a}$, Fei Zhao ${ }^{1, b}$ Guiyu Lin ${ }^{1, ~ c}$, Xiaochen Wang ${ }^{1, \mathrm{~d}}$, Haiqin zhou ${ }^{1, \mathrm{e}}$ \\ ${ }^{1}$ School of Mechanical Engineering and Automation, Northeastern University, Shenyang, China \\ 110819

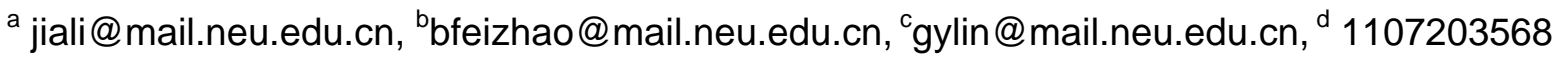 \\ @qq.com, ${ }^{\mathrm{e}}$ 806777583@qq.com
}

Keywords: Superlift mechanism, Linkage system, Size parameter, Optimization, Genetic Algorithm

\begin{abstract}
With the increasing demand for large-tonnage cranes in nuclear power and other industries, the research for cranes superlift is increasingly urgent. Taking 3500t crawler crane for instance, a new kind of hydraulic drive linkage system superlift mechanism is designed and a new design method for size parameters of linkage superlift mechanism based on genetic algorithm is proposed in this paper. Take minimum length of the luffing rod for the optimization target when superlift counterweight achieves the limitation position, according to the theory of linkage mechanism and crane structure and performance requirements, the constraints of linkage mechanism is established. By using design method which has been proposed to acquire length of luffing rods, MATLAB is applied to stimulate motion gesture of linkage superlift mechanism. The results show that size parameters of the luffing rods are reasonable, there is no dead spots in motion, and it can meet all design requirements. This paper provides a theoretical foundation and a new design approach for superlift mechanism of crane.
\end{abstract}

\section{Introduction}

With the rapid development of nuclear power, petrochemical, wind power and other industries, the requirements for large tonnage crane are urgent. In 2014, China Xugong Construction Machinery Co., Ltd. independently developed and manufactured the world's largest 4,000-ton crawler crane, which has completed 4500 t overload test successfully [1]. In 2012, the United States Bigge Lifting Rigging Ltd. launched the latest generation modular ring $7500 \mathrm{t}$ crane. An important system in large tonnage crawler crane is superlift mechanism. Superlift mechanism is installed between the mechanism and the main arm to improve the geometric relationship between the main arm and the plate, and guarantee the stability of the whole crane. Many large crane manufacturers have invested a lot of manpower and resources to conduct research for superlift mechanism and developed a variety of forms of superlift mechanism. There are two common forms of superlift mechanism, they are movable systems and suspension superlift mechanism. Movable superlift mechanism requires a relatively high quality of ground on which counterweight car can walk and its price is higher than the suspension superlift mechanism. Once lifting weight and working range of suspension superlift mechanism matching counterweight weight and counterweight amplitude, it can ensure the superlift counterweight leave the ground, walk and implement rotation work [2]. Currently, the suspension superlift mechanism has been proved to have many advantages and applied widely, while the design for size parameters of suspension linkage superlift mechanism is still lack of rational and systematic approach. In the paper, a new design method is proposed for size parameters of suspension linkage system which has important theoretical significance and application value.

\section{Crane Machine and Superlift Linkage System Mechanism}

The major advantages of the superlift system mechanism are as follows:(1) The structure is simple and easy to implement; (2) The linkage superlift mechanism can achieve a better self-adjustment of counterweight along with the host machine amplitude change, there is no need 
for a device to balance counterweight the car and track, and drive power can be completed through telescopic cylinders; (3) Linkage superlift mechanism can improve balance of crane, reduce main arm stress, simplify structure, reduce costs, lower weights, make crane design more rational and work safer.

In this paper, take one crawler crane for example to study, the two limit conditions of the crane design are as follows:(1)the length of main arm of lifting weight is $54 \mathrm{~m}$, working radius is $15 \mathrm{~m}$, suspension load is $3500 \mathrm{t}$; (2)the length of main arm is $123 \mathrm{~m}$, working radius is $60 \mathrm{~m}$, suspension load is 1340t. Considering the crane stability and overturn, the limit position of counterweight of superlift mechanism is $18.05 \sim 42.17 \mathrm{~m}$.

Whole Mechanism of Crane. The superlift mechanism of crane is designed according to the structure and performance requirements of the crane. Crawler crane consists of main arm 1, the rotary platform 9, walking system 10 and linkage mechanism. In linkage mechanism of superlift, the counterweight unit includes cylinder 4, luffing rod 1 and 2, counterweights 7 stacked on shelves. Hydraulic push luffing rod 1 and 2 to move, and then make the counterweight 7 move horizontally to meet the needs of different lifting weights and working radius. The mechanism is shown in Fig 1.

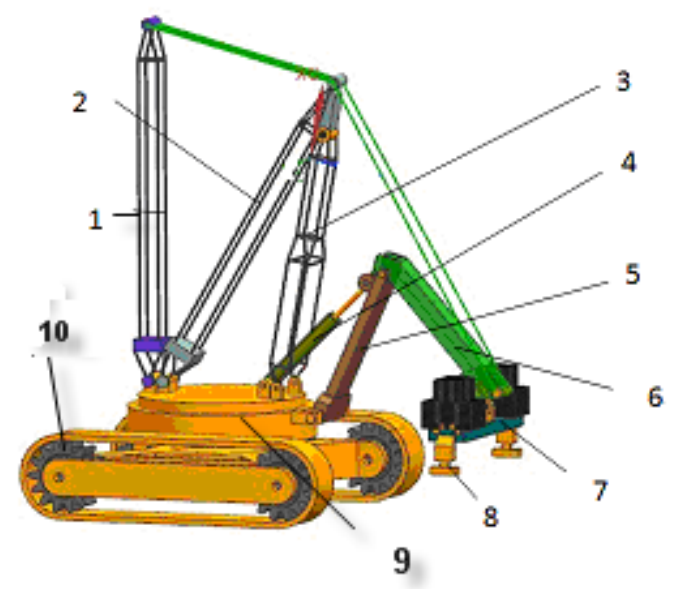

1.main arms 2.superlift mast 3.superlift bracket 4.cylinder 5.luffing rod 1 6.luffing rod 2 7.superlift counterweight 8 . cylinder telescopic bracket 9 . rotary platform 10 . walking system

Fig 1 The linkage superlift mechanism

Linkage Superlift Mechanism. Superlift system in whole machine is shown in Fig 1. The mechanics model of Linkage superlift mechanism separated from the whole machine is shown in Fig 2, composed of cylinder AC (Its function is to push linkage to move), luffing rod DE and EF. In the mechanism, crank $\mathrm{AB}$ represent the shortest length of the cylinder, $\mathrm{BC}$ represents the cylinder telescopic distance, DE represents the luffing rod 1, EF represents of luffing rod 2, point $\mathrm{F}$ represents the position of the counterweight, $\mathrm{DE}$ and $\mathrm{EF}$ are connected by hinge, point $\mathrm{A}$ and $\mathrm{D}$ are fixed point, coordinates of point $A$ is $(11.53)$, coordinates of point $D$ is $(15,0.78)$. When the cylinder implements telescopic movement, it leads luffing rod 1 and 2 reciprocating. According to kinematic transmission relationship of mechanism, the relationship between cylinder BC telescopic distance and counterweight position F point can be calculated [3].

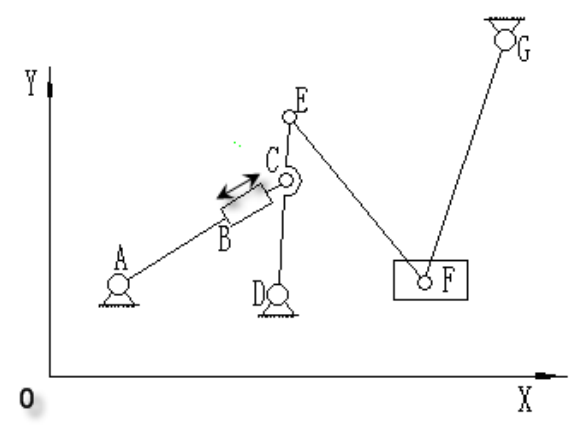

Fig 2 The mechanics model of the linkage superlift mechanism 
To meet machine stability and overturn requirements, the limit position of counterweight is $18.05-42.17 \mathrm{~m}$. Since the linkage rods push luffing rod through the telescopic cylinders, considering various manufacturing and assembly errors, the counterweight position is redefined by $42.3 \mathrm{~m}$.

\section{Design Method for Linkage Rod Superlift Size Parameters Based on Genetic Algorithm}

There is a common phenomenon of the local optimum in the traditional optimization approach. It is relatively difficult to find the globally optimal solution. The genetic algorithm can search random optimization in the entire region. In other words, it can evaluate and analyze multiple solutions in the searching space simultaneously, preventing the local optimal solution to achieve the global optimal solution effectively [4]. Applications of genetic algorithm led on to study design method for the linkage mechanism parameters and set up design model.

Design Factors and Target for Linkage Superlift Mechanism. In the linkage superlift mechanism, counterweight realize horizontal movement relying on rotation of luffing rod driven by the cylinder telescopic. Select $10 \mathrm{~m}$ as the shortest length of cylinder when the counterweight reaches the limit length of the cylinder of $17.3 \mathrm{~m}$. Set length parameter of luffing rod DC, CE and $\mathrm{EF}$ for the design factor to $\mathrm{x}_{1}, \mathrm{x}_{2}$ and $\mathrm{x}_{3}$ which determine mechanism geometry and kinematics characteristics.

In order to ensure counterweight of linkage superlift mechanism achieving the limit position $18.05-42.17 \mathrm{~m}$, taking account of the weight of the equipment, installation, manufacturing cost and so on, make the total length of the shortest link as the objective function, shown in the Eq 1.

$\min L=\min \left\{x_{1}+x_{2}+x_{3}\right\}$

Design range and constraints of linkage superlift mechanism. Considering weight, install, cost factors, range of linkage superlift system mechanism are show in Table 1.

Table 1 The range of variables for the linkage superlift mechanisms

\begin{tabular}{|c|c|}
\hline Design variable & Range of values \\
\hline$x_{1}$ & {$[14 m, 17 m]$} \\
\hline$x_{2}$ & {$[0.1 \mathrm{~m}, 1 \mathrm{~m}]$} \\
\hline$x_{3}$ & {$[14 m, 18 m]$} \\
\hline
\end{tabular}

According to linkage rod mechanism and crane and performance requirements, the constraints of linkage superlift mechanism are [5]:

(1) AC, CD, AD constitute a triangle, there is a relationship AC + CD>AD;

(2) DE, EF, DF constitute a triangle, there is a relationship DE + EF > DF;

(3)As limit movement range of counterweight is $18.05 \sim 42.17 \mathrm{~m}$, taking the manufacturing process and other errors into account, set limits movement of the counterweight to $17.5-42.3 \mathrm{~m}$;

(4) The left limit abscissa of point F is bigger than D;

(5) Ordinate of point $\mathrm{F}$ is constant;

(6) The angle range between rod $\mathrm{AB}$ and the horizontal line is $20^{\circ} \sim 85^{\circ}$.

Conformation of Genetic Algorithm and Parameter Design Results. Using genetic algorithm, the population size, the maximum evolution generation, lower and upper limit of each factor should be set. The larger the population, the better the gene diversity of the population, the stronger the global search ability, while the greater the amount of calculation, excessive population increase dramatically the amount of calculation and lower convergence rate. Therefore, the population size should be selected properly [6]. The larger the maximum evolution generation, the higher convergence accuracy, but too many generations will make amount of calculation larger, the training time longer. After verification and comparison repeatedly, set the population size of 300, the maximum evolution generation of 300, stagnancy generation of 30 , and input the upper and 
lower limit of factors onto the interface. After all the settings right, we can obtain the optimal solution.

According to the objective function and constraints, operate Matlab toolbox of genetic algorithm to calculate, the optimal results by programming are shown in Table 2.

Table 2 The parameter optimization results for the linkage superlift mechanisms

\begin{tabular}{cccc}
\hline Design variable & $x_{1}$ & $x_{2}$ & $x_{3}$ \\
\hline After optimization $(m)$ & 14.4269 & 0.5733 & 14.6519 \\
Objective function value $(m)$ & & 29.6421 & \\
\hline
\end{tabular}

\section{Superlift Kinematics Simulation}

Mechanism kinematics gesture analysis consists of five parts, modeling, solving, plotting diagram of the results, observing the solutions and adjusting the model. The first step is to establish model and list equations related components and key points, and then solve position data related point in the model, the third step is to use these data to establish diagram of motion process and the last step is plot a figure of gesture of linkage superlift system in motion [7].

In the motor process of linkage superlift mechanism, counterweight off the ground mainly depends on wirerope which ensures that counterweight moves horizontally. In process of gesture simulation, adding rope shown in Fig.2, FG represents the rope, to ensure counterweight maintain the horizontal movement basically, so the structure of the rope FG is retractable. gesture of linkage mechanism in a certain position is shown in Fig 2. The mathematical kinematics simulation model is established as follows[8].

For linkage mechanism, the distance between point A and D can be obtained.

$l_{A D}=\sqrt{\left(x_{D}-x_{A}\right)^{2}+\left(y_{D}-y_{A}\right)^{2}}$

In the Eq 2: $x_{D}$ - the horizontal distance of point $\mathrm{D}$;

$y_{D}$ - ordinate of point $\mathrm{D}$;

$x_{A}$ - abscissa of point A;

$y_{A}$ - ordinate of point A;

The angle between point $\mathrm{D}$ and point $\mathrm{A}$ :

$t_{A D}=\arctan \left(y_{D}-y_{A}\right) /\left(x_{D}-x_{A}\right)$

$\mathrm{AB}$ crank angle is:

$$
\begin{aligned}
t_{A B}= & \operatorname{acos}\left(\left(l_{A D}^{2}+\left(l_{A B}+d e l \times i\right)^{2}-l_{C D}\right) / 2 \times l_{A D} \times\left(l_{A B}+d e l \times i\right)\right) \\
& +\operatorname{actan}\left(\left(Y_{D}-Y_{A}\right) /\left(X_{D}-X_{A}\right)\right)
\end{aligned}
$$

In the Eq 4: $l_{A B}$ - the minimum length of the cylinder;

$l_{A C}$ - the maximum length of the cylinder;

$i$ - stretch length of the cylinder to equal parts;

del - the length of each part after dividing stretching length of cylinder equally

Rocker angle:

$t_{D E}=t_{A D}+\operatorname{acos}\left(\left(l_{A D}{ }^{2}+l_{C D}{ }^{2}-\left(l_{A B}+d e l \times i\right)^{2}\right) / 2 \times l_{A D} \times l_{C D}\right.$

The angle between rocker $\mathrm{EF}$ and $\mathrm{DE}$ :

$t_{D E}=\operatorname{acos}\left(\left(l_{E F}^{2}+l_{D E}{ }^{2}-l_{D F}{ }^{2}\right) / 2 \times l_{E F} \times l_{D E}\right.$

Based on the distance and angle of each rod from mathematical model, MATLAB is applied to plot a figure of linkage superlift motion gesture, scatter the equal length of the cylinder BC and gain the angle and position of mechanism in a discrete time [9]. The mechanism posture of simulation is shown in Fig.3. 


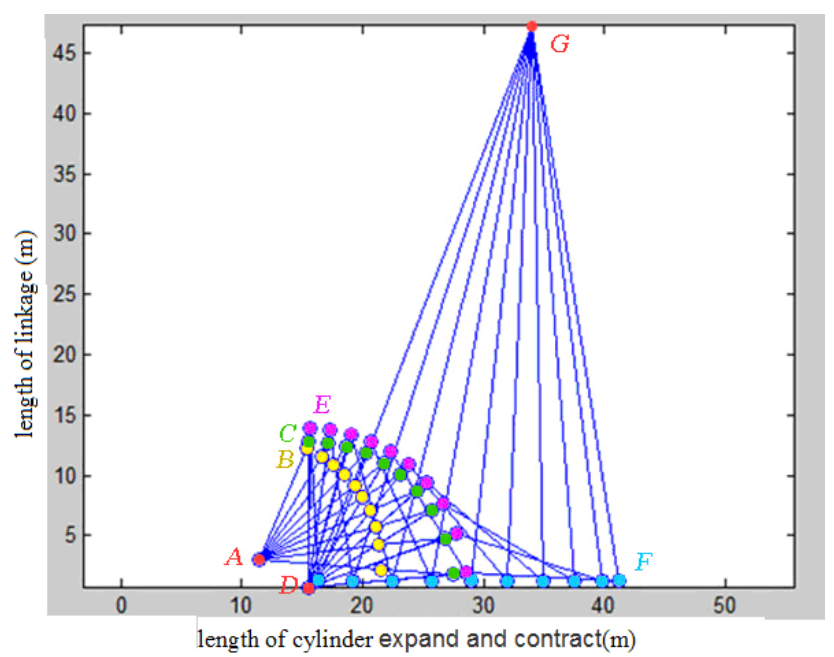

Fig 3 Posture simulation of the linkage superlift mechanism

The posture in process of motion can be seen from Fig 3. According to optimization parameters of the simulation, counterweight limit position are $15.21-43.14 \mathrm{~m}$, which meets range of functional requirements of $17.5-42.3 \mathrm{~m}$, so length of linkage rod is reasonable.

\section{Summary}

The demand for large tonnage crane is increasingly urgent in nuclear power, petrochemical and other industries. The superlift mechanism is to maintain stability and resist to the overturn in large tonnage cranes. Superlift mechanism of crane affects the performance and safety directly. This paper designs s kind of linkage superlift mechanism driven by telescopic hydraulic cylinder, which push luffing rod to move, so that the counterweight unit can move horizontally. This mechanism can meet different needs of working radius and lifting weights, improve the balance of the crane, reduce force on the main arms, simplify the structure, reduce cost, and lower weight. This paper also put forward design method for size parameters of linkage superlift mechanism based on genetic algorithm, regarding minimum length of luffing rods for the optimization target when counterweight of the superlift reaches the limit position. According to the theory of a linkage mechanism and crane structure and performance requirements, the constraints conditions of linkage rod of Superlift system is determined. Taking 3500t crawler crane for example, based on the proposed design method of optimization, superlift length parameters is acquired, applying MATLAB for implementing kinematics posture of linkage rod, simulation results verify the feasibility of the luffing rod parameters and the proposed design method. The results show that linkage rod size parameters are reasonable to ensure that there are no dead spots in motion and it can meet all the design requirements. The new design approach for the superlift of the crane has important theoretical significance and engineering application value.

\section{Acknowledgement}

This research is subsidized by the National 863 Project of China (Grant No.2012AA041804).

\section{References}

[1] Information on http://news.qq.com/a/20141003/010329.htm

[2] Xu Fengjun. Movable cranes superlift system Brief, Inner Mongolia Science Technology and Economy, Vol. (4) (2012), p 68-72.

[3] DJ Page JR Lucinschi. Crane with movable counterweight. China, Patent 102020210, (2011)

[4] Wang Shuren, editor. Computer-aided mechanical design, Northeastern University Press, Shenyang, (2001) 
[5] Lin Hede. crank-rocker mechanism with known linkage rod length and Two Kinematic positions based on genetic algorithm design, Dongguan University of College of Science and Engineer, Vol. 1(3)(2006),p59-63.

[6] Chen Jian, Ge Wenjie, Wang Junqiang, Zhang Songfei. Plane four-bar mechanism parametric design and motion simulation research and implementation, Modern Design and Advanced Manufacturing Technologies, Vol. 3(9)(2010),p25-30.

[7] Lei Yingjie, editor. Matlab genetic algorithm toolbox and application, Xi'an University of Electronic Science and Technology Press, Xi'an (2005)

[8] Wang Huajie. 4-bar mechanism motion analysis and animation simulation system based on MATLAB , Mechanical Design and Manufacturing,Vol. ( 05)(2005),p139-142.

[9]Wang Yongchao. Mechanism motion simulation method and comparison based on Matlab, Computer Simulation, Vol. (8)(2004),p 81-84. 